\title{
ÍNDICE DE HIGIENE ORAL EM PACIENTES ATENDIDOS NO SERVIÇO DE TRANSPLANTE DE MEDULA ÓSSEA DA UFPR
}

Natalia Medella de SANTANA, José Miguel AMENÁBAR, Cassius TORRES-PEREIRA

Pacientes portadores de neoplasias hematológicas ou doenças que levem ao mau funcionamento e/ou falência do tecido medular estão expostos a condições inerentes à doença ou ao seu tratamento que podem levar ao maior acúmulo de biofilme dentário e, conseqüentemente, maiores índices de cárie e doença periodontal (MAJORANA et al., 2000). O objetivo deste estudo foi avaliar o índice de higiene oral simplificado (IHO-S) (Greene e Vermillion,1964) e o índice de dentes cariados, perdidos e restaurados (CPO-D) dentre pacientes atendidos no Serviço de Transplante de Medula Óssea (STMO) da UFPR. Foram analizados 47 pacientes de pré e pós-transplante de medula óssea (TMO). Os dados coletados foram tabulados em planilhas do Excel e analisados através de medidas estatísticas de tendência central, correlacionando-os com pacientes não-TMO. Pacientes em situação de pós-TMO manifestaram IHO-S médio de 1,60, sendo este dado superior a média observada em pacientes pré-TMO (média de 1,42). A média do índice CPO-D foi de 9,51 sendo positivamente correlacionado com a idade do paciente. Os resultados sugerem que o controle mecânico ou químico de biofilme dental seja objeto de abordagem profissional em serviços que atendam este perfil de paciente, com ênfase em estratégias de educação para o autocuidado e promoção de saúde.

Palavras-chave: Índice de Higiene Oral; Transplante de Medula Óssea; Estomatologia. 